\title{
Social Media for Enhancing Civil Society and Disaster Relief: Facebook Usage by Local Municipalities in Japan
}

\author{
Muneo Kaigo*, Leslie Tkach-Kawasaki*
}

*Faculty of Humanities and Social Sciences, University of Tsukuba, 1-1-1 Tennodai Tsukuba Ibaraki 3058571 Japan, \{mkaigo, tkach\}@japan.tsukuba.ac.jp, 81-29-853-4037

Abstract: This paper describes a case study that analyzes social media usage by a local municipality in Japan, and discusses the possibilities and problems of complementary communication channels such as social networking services for promoting civil society activities and linking civil society organizations. We examine how, in the past, Japanese municipalities have been using social media and social networking services for enhancing civil society and how SNS (social networking services) are a potential tool that can provide vital information and connect citizens, governments and civil society. This article focuses on the first phase of the Tsukuba Civic Activities Cyber-Square [Tsukuba Shimin Katsudō no Hiroba] on Facebook Experiment early in 2012 and how it functioned during and after the May 6, 2012 Tsukuba city tornado disaster for subsequent relief and support activities.

Keywords: Japan, municipalities, civil society, social networking services, e-government, natural disasters

Acknowledgements: We would like to thank Mr. Kazuho Okano and Ms. Masaki Nada of the Tsukuba municipal government, as well as Intel Co., for assisting and cooperating with our research, and the University of Tsukuba for partially funding this study. We would also like to thank Ms. Won-Young Jang for assisting in our data analysis for this study. In addition, we are truly grateful to the anonymous reviewers who provided constructive comments on earlier drafts of this article. This study is based on a paper originally presented at CeDEM Asia 2012. Completion of this study was partially supported by JSPS KAKENHI Grant Number 25330394.

\section{Introduction}

This article analyzes social media usage by local municipalities in Japan, focusing on the possibilities and problems of complementary communication channels such as social networking services. Rapid transmission allows social media to facilitate communication activities in new ways and offers new avenues for information interaction between citizens and local governments. One example is the micro-blog Twitter, and citizen followers of a local government's Twitter account can receive updates continuously about public services and events. Other SNS platforms 
such as Facebook allow citizens to experience more personal connections with their local governments. These types of online relationships do not demonstrate powerfully committed personal bonds, but weak links (Resnick, 2002; Wellman et al., 2001) that acknowledge the existence of a connection without requiring a strong bond among people using social media. If strong bonds exist among users regardless of social media, then they can mobilize people, as in the case of the 2010-2011 Arab Spring political movements (Howard, et al., 2011; Howard and Parks, 2012; Kaigo, 2012). In general, just like websites, social media usage efficiently reduces distances between people and effectively connects members of modern society.

In the immediate aftermath of the Great East Japan Earthquake that occurred on March 11, 2011, voice communication through normal telephone lines was difficult in affected areas due to the initial congestion caused by the sudden increase of calls. As is natural in many disaster-related situations, many people became alarmed and nervous, needing reassurance that their loved ones were safe. Some needed to convey delays or cancellations due to transportation disruptions. In contrast to fixed telephone lines, Internet access through mobile devices was found to be relatively robust and resilient in comparison to the normal telecommunication channels (Kaigo, 2012). Voice over IP, SMS (Short Message Services) and email are quicker solutions for communication and overcoming telecommunication breakdowns or congestions in such disasters. Radio is more effective due to its portability and ability to function with batteries in comparison to televisions that are of no use during power outages. Social media such as Facebook and Twitter have proved more effective in disseminating information through the Internet rather than websites hosted on local servers that were damaged or non-functioning due to power outages early in disasters such as the southern California wildfires and the Sichuan earthquake in 2008 (Sutton et al., 2008; Mills et al., 2009), and hurricanes that hit the Atlantic coast in the U.S. in the same year (Hughes \& Palen, 2010). White (2010) has also discussed the role of social media in crisis-mapping during local-level disasters. Twitter was found to be most effective for quickly spreading information-whether true or false-in Japan during the Great East Japan Earthquake (Kaigo, 2012). Kaigo (2012) examined how Twitter has the potential to transmit false rumors very rapidly in Japan during disasters, therefore Twitter usage requires some further consideration on how to avoid some of the unfavorable consequences that were observed during the Great East Japan Earthquake in 2011.

Following the Great East Japan Earthquake, many Japanese municipalities began experimenting with various social media other than Twitter, such as Facebook. As power outages affected local servers that were hosting Internet services in Japan, the Great East Japan Earthquake demonstrated how many of the expensive customized local SNS platforms were of no use during times of unstable power supply, particularly as many areas were required to conserve energy via planned power outages after the Great East Japan Earthquake. Such situations were unimaginable before the disaster and served as catalysts to change the minds of conservative decision-makers within Japanese municipalities to outsource SNS platforms instead of constructing their own local SNS platforms. During the Great East Japan Earthquake, researchers observed that through social media, a communication network of social support was formed in municipalities experiencing mid-level disruptions, and social interaction was made possible throughout a wide region (Hashimoto and Ohama, 2014; Inoue, 2013). Social media became an information conduit and knowledge source for the citizens of Japanese municipalities with mid-level disruptions in the 
early days after the disaster. This practical utilization suggests that this observed means of transmitting and receiving information is effective and potentially beneficial as a channel for municipal government communications.

Given this potential, in this article, we examine how the city of Tsukuba in Ibaraki prefecture utilized Facebook regularly on a trial basis for a six-month period in early 2012 as a means of enhancing social capital among its citizens. This city's experience is rather unique, as during the experimentation period, it experienced its own local disaster when a tornado ripped through the north part of the city in early May 2012. Thus, the time period allows us to investigate the regular use of social media as a means of communicating local-government information, as well as its use during a disaster situation. After examining the literature on social media, its relationship with social capital, and the background of social media and its use among municipalities in Japan, we look at the Tsukuba Civic Activities Cyber-Square Experiment conducted by the City of Tsukuba in early 2012 and the events of the May 6, 2012 tornado. In our discussion section, we review the implications of the six-month experiment, the use of social media during the tornado disaster, and contemplate the possibilities of social-media utilization on the local government level in Japan to enhance the government-to-citizen relationship.

\section{Social Capital, Social Media and Social Design}

The concept of social capital (Putnam, 2000) is useful as a means of investigating the relationship between Internet use and (potentially enhanced) civic participation. Certain research claims that the Internet encourages social connections and involvement, upending prior fears of a decrease in social involvement or social displacement (Valkenburg \& Jochen, 2007). The case of social media is the same, as studies indicate that social capital is greater among those who actively use SNS ( Steinfeld et al., 2008, Ellison et al., 2011; Lampe et al., 2007; Pfeil, et al., 2009). Kobayashi and Ikeda (2005) also have observed trust and reciprocity as social capital elements in ICT (Information and Communication Technology) usage in the Japanese context. Social capital is formed through the social contexts of trust, norms, and networks to make a more efficient society by promoting the resources that exist in the harmony among positive human relationships (Putnam, 2000). Exchanges of ideas during times of difficulty build human relationships and demonstrate a means by which communication activities build social capital. Putnam (2000) has termed bridging and bonding to be the two ways of building social capital, however when viewing this idea in the perspective of SNS-based communication activities, these two separate types of social capital may both be present. Communication that bonds close individuals may occur in SNS, but bridging among diverse individuals is equally possible with SNS; thus the intermix of the two types of building social capital needs to be considered as well (Kaigo, 2012).

Another approach directly related to the theme of this study is "social design" that explains the process of citizen involvement in community building and effective steps in tackling social issues in Japan (Kakei, 2013). Social design is related to the Japanese concept of machizukuri (literally translated as "building community") as a means of encouraging local residents to participate in their local communities (Kusano, et al., 2014). As communication among residents is one of the 
core concepts, practical approaches-rather than theoretical constructs-are integral in developing and using online social spaces where residents can interact to tackle problems or issues.

The enormous economic growth and population increase in Japan during the 20th century has now been replaced with the decline of both in recent years. This reversal of economic and population growth has led local policy-makers to revise many previously uniform and standardized approaches to dealing with various social issues. Declines in tax revenue have led to cuts in budgets and government personnel. Management of social issues by the public sector alone is no longer possible in Japan, and this situation has offered opportunities for many citizen organizations and NPOs (non-profit organizations) to assume some of the roles that have traditionally been thought to be the responsibility of local Japanese governments. In this new fiscal environment, policy-makers need to focus more on constructing and designing social systems that take advantage of available resources that enable them to accomplish their tasks, rather than creating new schemes or continuing to build new departments or structures. Many social actors share the same concerns towards society and each can play a role in building communities. Social design enables these social actors to communicate and share their concerns towards society and allow for coordination to actively use available resources and people (Kakei, 2013). Many local governments in Japan are in need of such social design due to the increasing number of social issues that need to be addressed to help maintain local communities. One way that social design can be applied to local governments in Japan is to implement social media as a means of connecting civil society. As social media such as SNS can be used to virtually connect a new variety of social actors simultaneously, social issues can be shared simultaneously through social media and all actors can begin participating and communicating with one another to address what needs to be done. Overall declines in social capital discussed by Putnam (2000) can be avoided in Japan by using social media in the process of redesigning the concept of "community."

\subsection{Social Networking Services in Japan: mixi to Facebook}

The definitions and history of social networking services have been well documented and there have been various comparisons of platforms in different contexts (boyd \& Ellison, 2007; Raacke \& Bonds-Raacke, 2008). In Takahashi (2010), the Japanese audience engagement with SNS in the social context has been previously concluded to have the following four dimensions: 1) information-seeking activity, 2) connectivity, 3) bricolage, and 4) participation, through an ethnography of users of the Japanese SNS mixi and MySpace. Takahashi states that Japanese SNS use has more of a collective dynamic (with a focus on "us"), in comparison to such networking sites initially developed in the U.S. such as MySpace, which is more about the individual user (oneself or "me"). Takahashi also explains the constructs of uchi (inner) and soto (outer) to explain how users attribute individual properties to their online personas in different platforms while often simultaneously using pseudonyms. The web interface of mixi also creates a boundary that reflects society, and this interrelates with preexisting cultural behavior and distinctions between ethnic groups online. However, these results are now facing a new development or transition, as mixi and MySpace are no longer the dominant SNS in Japanese and U.S. cyberspace. 
In regards to previous research on social media increasing civic participation, MacAtee \& Wolak (2011) discuss social networks and motivation for participation in civil society. The emergence of a network society allows for everyday online communication and interconnectedness (Wellman \& Haythornthwaite, 2002). Virtual communities have the following shared traits of 1) space, 2) shared practice, 3) shared resources and support, 4) shared identities and 5) interpersonal relationships (Baym, 2010; Wellman et al., 2003). Previous research has expressed expectations of how virtual communities could help civil society function more effectively through the development and diffusion of online social networks (Jennings \& Zeitner, 2003; Livingstone \& Markham, 2008; Shah, Cho, Eveland \& Kwak, 2005; Shah, McLeod \& Yoon, 2001).

According to a report by Nielsen Netview of Japan, in March 2013, among the various SNS in Japan, Facebook had the most unique visitors, totaling $17,515,000 .{ }^{1}$ In contrast, mixi, formerly the most dominant social network in Japan, had only 4,468,000 visitors in the same month. In comparison, data from July 2011 reports 14,033,000 visitors to mixi and 9,504,000 visitors to Facebook, showing that within two years, the SNS usage ratio changed dramatically in Japan. In less than two years, the number of users of each service changed rapidly, resulting in Facebook being the most popular SNS in Japan by March 2013. Due to its increase in acceptance, many organizations and municipalities in Japan subsequently initiated projects to consider or implement Facebook usage for better civic engagement.)

\subsection{Social Networking Services for Municipalities in Japan}

The use of Internet-based functions is not new in Japan, as many municipalities are using email newsletters for information dissemination such as safety alerts and weather advisories. According to the Ministry of Internal Affairs and Communications, as of April 2014, 93.6\% of larger administrative structures such as large cities and prefectures in Japan distribute email newsletters and $22.8 \%$ of smaller administrative structures (small cities, towns, and villages) utilize this function for one-way information distribution (MIC, 2014). According to survey results by the Ministry of Internal Affairs and Communications in 2013, 35.2\% of the local governments in Japan use websites, $28.3 \%$ use a commercial SNS (i.e., Facebook) and $29.1 \%$ use blogs or micro-blogs (i.e., Twitter) for communication (MIC, 2013). As for reasons, $86.5 \%$ use social media for communicating to residents and local businesses, $72.7 \%$ for disseminating information to nonresidents, and 58\% have started using social media in case of disasters. Furthermore, usage of social networking services for promoting municipalities can be observed in Japan, similar to examples in other nations such as Spain (Kiss, 2015).

One noteworthy example in Japan is the case of Takeo city of Saga prefecture, located in southern Japan. Takeo city has switched from using traditional websites to featuring its Facebook page as its main Internet presence. Takeo city has a history of progressive use of social media such

\footnotetext{
${ }^{1}$ http:/ / www.netratings.co.jp/solution/netview.html
} 
as Twitter. For example, by 2010 it had provided Twitter accounts to a majority of its workers and has been encouraging them to post tweets, contrary to the policies of many corporations that prohibit using Twitter during working hours. The local government's aim was to promote the flow of ordinary information from the government so that citizens could feel closer to their municipality. During the flooding that occurred in the Takeo area on June 12, 2011, the mayor and other workers continued sending out disaster information about road blocks and flooding, and subsequently were able to raise over 1 million yen in donations in part thanks to communicating their relief efforts via Twitter. Their success in using Twitter evolved into tactics for further enhancing visualization of the workings of the municipal government, and eventually they expanded their online presence to utilizing Facebook.

Takeo city provides information on services for residents such as child-rearing support, general safety, tourist information, and business or procurement information. Using inline frames, the municipality embeds local government information in Facebook, but also uploads such pages onto a server outside of Facebook to avert risk in case of service failure or changes in Facebook policy. Their Facebook page is set to open access to those who do not have Facebook accounts. Communication is facilitated between the government and Facebook account holders who can comment on and "like" any updates posted by the city.

Using Facebook has certain merits for local governments. It allows for quicker service, more accountability, lower IT server maintenance costs, and greater opportunities for interactivity among citizens and the government. However, there are also potential demerits: Facebook implementation may be intimidating to citizens with varying levels of digital skills (IT literacy or computer literacy). Furthermore, to ensure fairness to all citizens regardless of digital literacy levels, local governments must also consider balancing information provision to address potentially different levels of interest in civic activities among citizens. There is risk involved as well, in the case Facebook, as some services may be phased out or policy changes concerning privacy and personal information. Such concerns about platform durability may inhibit new users from joining the service. In Japan, where government polls have identified the potential for misuse of personal information to be the most important concern among users overall (MIC, 2013), entrusting their personal or private information shared with Facebook is a particularly relevant issue. Despite the low risk, some entries are potentially subject to trolling by other Facebook users.

In viewing both the pros and cons of implementing Facebook services, many Japanese local municipalities have determined that the benefits outweigh the risks in incorporating Facebook usage into their daily operations. They have initiated or are currently planning to create Facebook pages to provide fora for citizens and government so that community members can exchange ideas (MIC, 2013). This article focuses on one case in Ibaraki prefecture-specifically, the Tsukuba Civic Activities Cyber-Square Experiment [Tsukuba Shimin Katsudō no Hiroba]-of the Tsukuba municipal government of Japan. 


\section{Tsukuba Civic Activities Cyber-Square Experiment}

The Tsukuba municipal government of Ibaraki Prefecture in Japan is located approximately 60 kilometers northeast of Tokyo, the capital of Japan. This municipality has been working with the University of Tsukuba and Intel Corporation to create the Tsukuba Civic Activities Cyber-Square with the self-defined goals of 1) nurturing future human resources and cultivating entrepreneurship, and 2) reactivating communities and recreating a healthy civic life by the year 2015. With these objectives in mind, in 2012, the Tsukuba municipal government began an empirical experiment to promote cooperation among citizens by creating a new perspective among citizens through social media. To facilitate this, the municipality set up a "cyber plaza" or "cybersquare" to help promote networking among civic activities and groups. This cyber-square was initiated to create a foundation for information sharing and help visualize civic activities for enhancing civil society within the city. Prior to commencing this experiment, Tsukuba city had the highest number of Facebook users in Ibaraki with approximately 10,860 users in October 2011, through access to the Facebook statistics that were available through the advertising interface that provides the number of users that have indicated Tsukuba as their domicile in their profile. With these intentions, this experiment was initiated in January 2012 and ended its first phase at the end of June 2012. With its success, social media usage has been integrated in the city's operations in cooperation with the University of Tsukuba.

In this section, we report on this preliminary phase of the experiment by first comparing the types of activities featured on this Facebook page as well as other Facebook pages operated by municipalities or groups within Ibaraki prefecture. Then, we quantitatively examine the posts in the Tsukuba Civic Activities Cyber-Square from January 20 to June 30, 2012 that refer to social capital factors using SPSS computer-assisted text analysis (see below). During that period, Tsukuba city experienced a local disaster on May 6, 2012 in the form of a rare tornado storm. Thus, within our analysis of the city's experimental period with Facebook, we also had the opportunity to assess firsthand how community information provision and communications through Facebook played a vital role during the emergency situation from May 6 to May 31.

\subsection{Comparison with Other Social Networking Services in Ibaraki}

In order to situate the city of Tsukuba's Facebook page among other locally operated Facebook pages in Ibaraki prefecture, we identified the top five Facebook sites in the same prefecture at the time of the first phase of the experiment from January 20 to June 30, 2012 (see Table 1). Our selection criteria included sites that were either being operated by prefectural-level or local governments, or Facebook pages that had been in existence for a similar or longer duration than the city of Tsukuba's Facebook page. 
Table 1: Top Five Facebook Sites Originating in Ibaraki Prefecture (January to June 2012)

\begin{tabular}{|l|l|l|c|}
\hline Page title (English) & $\begin{array}{l}\text { Page title } \\
\text { (Japanese) }\end{array}$ & Operating Entity & $\begin{array}{c}\text { Likes as of June 30, } \\
\mathbf{2 0 1 2}\end{array}$ \\
\hline $\begin{array}{l}\text { Tsukuba Civic } \\
\text { Activities Cyber- } \\
\text { Square }\end{array}$ & $\begin{array}{l}\text { Tsukuba Shimin } \\
\text { Katsudō no Hiroba }\end{array}$ & Tsukuba city & 1263 \\
\hline Foodies in Ibaraki & $\begin{array}{l}\text { Umaimono dokoro } \\
\text { Ibaraki }\end{array}$ & $\begin{array}{l}\text { Ibaraki prefecture, } \\
\text { Agricultural and } \\
\text { fisheries } \\
\text { distribution } \\
\text { department }\end{array}$ & 907 \\
\hline $\begin{array}{l}\text { Enchantment of } \\
\text { Ibaraki }\end{array}$ & $\begin{array}{l}\text { Ibaraki no miryoku- } \\
\text { o tsutatetai }\end{array}$ & $\begin{array}{l}\text { Ibaraki prefecture, } \\
\text { Public relations } \\
\text { department }\end{array}$ & 863 \\
\hline Mito City Tourism & $\begin{array}{l}\text { Mito-shi kankōka } \\
\text { Mitoshikankōkyōkai }\end{array}$ & $\begin{array}{l}\text { Mito city, Tourism } \\
\text { board }\end{array}$ & 286 \\
\hline Sakuragawa City & Sakuragawa-shi & Sakuragawa city & 491 \\
\hline
\end{tabular}

The majority of the sites were focused either on promoting a particular feature of Ibaraki prefecture or tourism within the prefecture. For example, the "Foodies in Ibaraki" page concentrates on promoting local delicacies, as well as popular restaurants and eateries. "The Enchantment of Ibaraki" page focuses on encouraging tourism in Ibaraki by including information on local events, seasonal topics, popular tourist spots, and accommodation. The "Mito City Tourism" page is also about tourism, providing local information about the city of Mito (the capital of Ibaraki prefecture), its history, and its traditions. The "Sakuragawa City" page is a Facebook page that is more general in terms of content, offering information and topics about Sakuragawa city, tourist information about the area, as well as listing restaurant information and popular places for families to visit. Among the top five sites, the Tsukuba Civic Activities CyberSquare is the only page that focuses solely on civic activities and civil society. Due to the lack of Facebook pages in Japan with similar focus on such activities at the time of the experiment, the four tourism-oriented Facebook pages were selected for comparison.

Figure 1 shows a comparison of the total number of posts on the five Facebook pages during the period from January to June 2012 when the Tsukuba Civic Activities Cyber-Square was in its initial experimental phase. 
Figure 1: Total Posts on the Top Five Facebook Pages in Ibaraki, January to June 2012

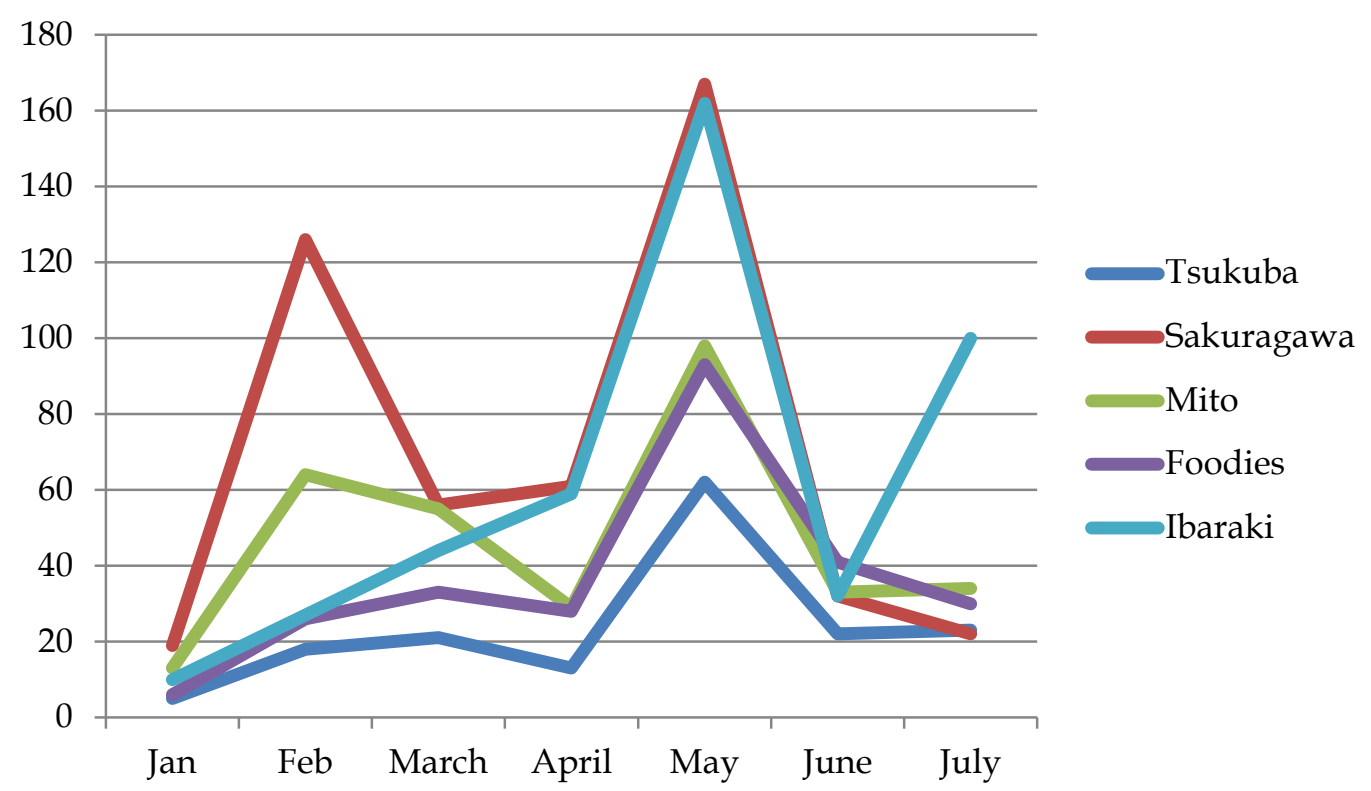

As noted earlier, providing tourism-related information, which is essentially oriented towards information provision rather than communication, was the main focus of four out of the five Facebook pages. In our assessment of the Facebook sites, we discovered that the sites that provided information regarding tourism or food (information on four out of the five Facebook sites that could be directed at a broad range of people including residents or visitors) were likely to have more posted comments and likes in comparison to information aimed at residents (such as that posted on the Tsukuba city page).

For example, in terms of tourism-related information, the increases in the number of posts in the Sakuragawa and Mito Facebook pages during February 2012 can be attributed to drawing potential visitors to local events such as the Makabe Hina matsuri (Makabe Doll Festival), a traditional local event that celebrates the Japanese custom of "Girl's Day" in early February, and the Sakuragawa annual marathon. Similarly, in Mito city during February 2012 and into early March, the majority of postings focused on the Mito city plum blossom festival, an eight-day festival that was held on four consecutive weekends from February 18 to March 11, 2012 and featured various theme events related to plum blossoms. The festival celebrates Mito city's official flower that figures prominently in the city's Kairakuen municipal park, known for being one of the three most beautiful municipal parks in Japan. All four tourism-related sites showed spikes in activity during the period late April to early May, coinciding with the "Golden Week" holiday period (wherein there are four national holidays occurring within the period April 29 to May 5), a popular period for domestic travel. Among the five Facebook sites, Figure 1 also shows that the Tsukuba Civic Activities Cyber-Square had a competitive amount of posted comments and likes in comparison to the other four pages in consideration of the characteristics of information being communicated.

In terms of information provision, Facebook pages can be used in a similar manner as websites wherein the owner of an open Facebook page can transmit information to a broad audience. 
However, the engagement opportunities that are built into Facebook's architecture, such as the liking, commenting, and sharing features for viewers or users to interact with the owner of the page in real time, offer enhanced communications. Thus, we also assessed Facebook's engagement functions for the five Facebook pages (Figure 2).

Figure 2: Engagement Features (Total of Likes, Comments, and Shares) on the Top Five Facebook Pages in Ibaraki, January to June 2012

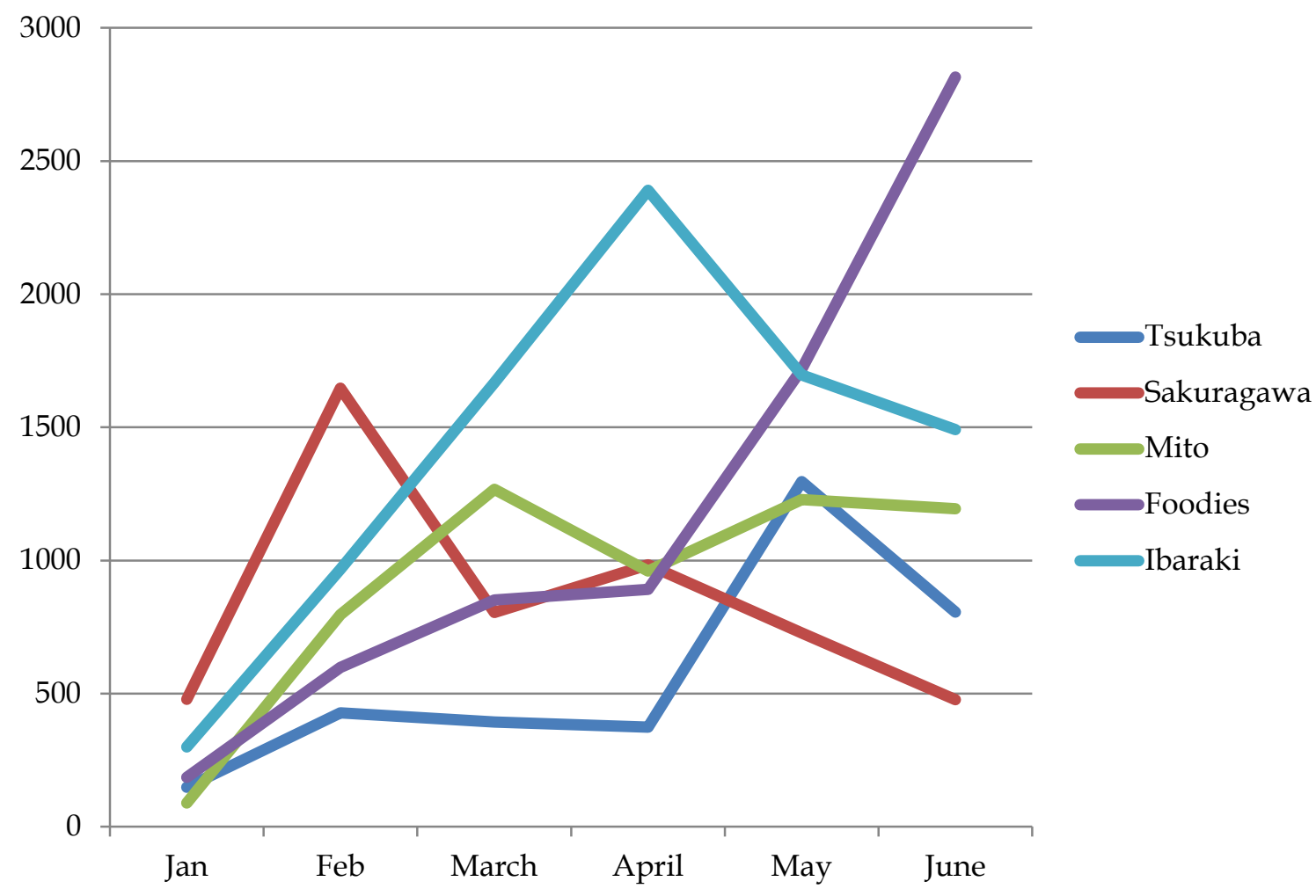

As illustrated in Figure 2, a sudden increase can be observed during May 2012 in the Tsukuba Civic Activities Cyber-Square. Although the number of posts by the four other Facebook pages are greater than the Tsukuba Civic Activities Cyber-Square from January through April, access to engagement features surpasses the Sakuragawa page for May and June as well as the Mito page. The increase in online engagement after May 6, 2012 in the Tsukuba Civic Activities Cyber-Square is due to the tornado disaster that occurred around 13:00 that day which resulted in outages affecting 20,000 residences and deaths and injuries, along with destruction of homes and other facilities (this disaster will be examined in detail later).

From this analysis, we observed that among the pages we selected, 1) social networking service pages that communicate tourism-related or recreational information are more likely to have comments posted or be liked, however, 2) social networking service pages that focus solely on communicating civic, resident-oriented, and government-provided information may be considered effective for increasing spontaneous feedback, such as comments or likes on Facebook. 


\subsection{Analysis of Posts on "Tsukuba Civic Activities Cyber-Square"}

The Tsukuba Civic Activities Cyber-Square Facebook page had a total of 109 posts (inclusive of updates and also comments to updates) from January 20 to June 30, 2012. We divided the overall contents into two broad categories: The first category concerns posts related to everyday life (62 posts) and the second category is made up of content posted in reaction to the May tornado (47 posts). Computer assisted text analysis has been used in studies to analyze sentiment in the past (Park et al., 2011), therefore, we used SPSS Text Analytics for Surveys 4.0 to analyze all postings morphologically after extracting the data. In this section, we first assess the posts related to everyday life in Tsukuba to find communality with concepts related to social capital, such as community, public interest, social participation, and civic participation.

Computer-assisted text analysis allowed us to assess the 62 posts regarding everyday life that were made to the Tsukuba Civic Activities "Cyber-Square" during this period in terms of morphemes that reflect features of social capital. Table 2 shows the overall results of the morphemes that were extracted from the posts.

Table 2: Analysis of Posts in Tsukuba Civic Activities Cyber-Square

\begin{tabular}{|l|c|}
\hline Morpheme & $\begin{array}{c}\text { Total posts (N) } \\
\text { and \% }\end{array}$ \\
\hline Gratitude & $27(43.5 \%)$ \\
\hline Requests & $16(25.8 \%)$ \\
\hline Affirmation & $8(12.9 \%)$ \\
\hline Delight & $6(9.7 \%)$ \\
\hline Encouragement & $5(8.1 \%)$ \\
\hline Total & $\mathbf{6 2 ( 1 0 0 . 0 \% )}$ \\
\hline
\end{tabular}

Posts that reflected gratitude (27 posts, $43.5 \%$ ) and requests (16 posts, $25.8 \%$ ) made up more than two-thirds of the total number of posts. Among the examples that we extracted, expressions of gratitude include phrases such as "Volunteering like this is welcome" and "Thanking you always." These two types of postings, comprising close to $70 \%$ of the total number of posts in the "everyday life" category, were deemed to reflect social support and reciprocation among the users of the Tsukuba Civic Activities Cyber-Square. The third type of posting, which we termed "affirmation," accounted for more than $10 \%$ of the posts, and we considered these types of posts to reflect a positive image towards the Cyber-Square Facebook page. Positive feelings regarding the local area (Harper, 2002) were demonstrated by the 6 posts $(9.7 \%)$ that expressed "delight." Finally, the social capital features of reciprocity and trust were illustrated by the 5 posts $(8.1 \%)$ that were categorized as "encouragement." 


\subsection{Social Capital through Updates}

The results of the comparison of the activities within the Facebook page of the Tsukuba Civic Activities Cyber-Square and the other Facebook pages being operated by municipalities in the vicinity show that the total number of posts are lower overall in the Tsukuba Civic Activities Cyber-Square when compared to the other pages with "recreational" content. However, as described earlier, the Tsukuba Civic Activities Cyber-Square has been proven to be effective in nurturing social capital through a computer-assisted text analysis of the posts made in the Tsukuba Civic Activities Cyber-Square. Even without making the content artificially "recreational," communication to enhance civil society through social networking services has been demonstrated to be a viable option. Through the example shown earlier, the Tsukuba Civic Activities Cyber-Square Facebook page can gain attention equal to the other Facebook pages of local municipalities in the same region.

Assessing posts during the month after the natural disaster in the Tsukuba area demonstrates that civic related information such as disaster relief communication and civic activity notices are equally valuable for users of SNS with such orientation, and can be competitive when comparing the number of likes or comments. Municipalities need not post "recreational" or tourism-oriented information continuously to elicit instantaneous reactions such as likes or potentially superficial comments to their updates. People who have or who developed an interest in the communications of the municipality will "like" the page and subscribe to the disseminated information. It is possible that when first accessing the page, a user might be a "silent subscriber," or someone who reads posts but does not react or comment on them. This may continue until a time comes when the subscriber feels the need to comment or communicate in another way. When a person is motivated to communicate and participate in communications involving the municipality, the person becomes more involved in the community, in this case, through civic activities. This interest can resonate from cyberspace back into real society. This cycle of interest and involvement demonstrates the possibility of SNS usage among the local municipalities in Japan. We shall now examine the flow of "civic" information of disaster relief communication during the Tsukuba Tornado disaster in further detail.

\subsection{The May 6, 2012 Tsukuba Tornado (Tsukuba, Ibaraki)}

In comparison to other regions of the world, while not unheard of, tornados in Japan are relatively rare, according to the Japan Meteorological Agency. Tornado sightings in Japan are not regionally isolated, and therefore, they may occur anywhere throughout the country. In the five-year period spanning 2005 to 2011, 116 tornados were recorded (on average, 23.2 per year, not including tornados on the ocean) by the Japan Meteorological Agency. Tornados occur most often in September and October, known as the typhoon season in Japan, and are relatively rare from January till May in comparison.

On May 6, 2012, at approximately 13:00, the southwest area of Ibaraki prefecture (where the city of Tsukuba is located) and southeast area of Tochigi prefecture were struck by a powerful tornado storm. The tornado took a northeast route, first heading into the Hojō area in the north part of Tsukuba and then continuing in a northerly direction to neighboring Tochigi prefecture. Factories 
and buildings located in Tsukuba city's northern industrial area as well as the Hojo area were destroyed or had their roofs blown away. Ultimately, approximately 2,000 buildings and homes were damaged, with Tsukuba city being the hardest-hit area in terms of overall damage. According to the Ministry of Internal Affairs and Communications of Japan, over 800 houses were damaged and 170 were completely destroyed. One person was buried alive in a house collapse and subsequently died. Immediately after the tornado, power outages affected 21,000 homes and continued in the area for several days. Damage to water supply systems meant that close to 5,200 homes also temporarily lost water access.

The Japan Meteorological Agency observed so-called "supercell" thunderclouds 2 due to a cold air mass over Japan developing at the time of the tornado occurrence (The Daily Yomiuri, 2012). According to the Fujita-Pearson Tornado Scale, or F-Scale (a six-level ranging from F0 being the weakest to F5 as the strongest), the tornado in Tsukuba was categorized as a F2 tornado with winds of more than 50 meters per second or $180 \mathrm{kph}$, and may have been temporarily as strong as an F3 in some areas (The Daily Yomiuri, 2012). The most powerful tornados ever recorded in Japan have been F3 tornados, such as the November 7, 2006 tornado in Hokkaido, the September 24, 1999 tornado in Aichi Prefecture and the December 11, 1990 tornado in Chiba Prefecture, which tore down houses and upended train cars.

\subsection{Tsukuba Civic Activities Cyber-Square and the Tornado}

After the initial sighting and confirmation of the tornado hitting the northern area of Tsukuba city, the Tsukuba municipal government immediately went into action. The city government very rapidly created a disaster response center in its main Municipal Hall. Through these circumstances, the Tsukuba Civic Activities Cyber-Square Facebook page immediately took an emergency communications channel role during its experimental phase from May 6 to May 26, 2012, as it evolved into one of the essential information tools of the Tsukuba municipal government for sending out and collecting information pertaining to the tornado.

Figure 3 shows the number of postings during this three-week period. A posting by the municipality notifying residents that a tornado had hit the northern area of Tsukuba on May 6, 2012 had a reach of over 1000 with subsequent postings of the damage of the area. A subsequent posting on May 6, 2012 included a notification that an operations center had been established at the Tsukubane citizens' hall in northern Tsukuba with first-aid facilities. On May 7, the day after the tornado, volunteers were being recruited along with postings through Facebook of information about volunteer and clean-up activities. The procedures for accepting waste materials from the disaster were also being communicated via Facebook. On May 8 and 9, notices regarding volunteer activities and relief materials were also posted. On May 10, more detailed information related to the May 6 tornado started being reported through the Facebook page along with a new weather alert of another possible tornado that same day. On May 11, the Tsukuba Civic Activities Cyber-

${ }^{2}$ http:/ / www.srh.noaa.gov/bmx/?n=supercell 
Square made a posting about availability of the Hojō Machikado newspaper, printed to allow residents without Internet access to obtain information. (The Hojō Machikado newspaper is published by the local area promotion board.) The Facebook page also informed citizens of extended working hours of municipal consumer support centers and sent out warnings about uniformed swindlers impersonating municipal workers, trying to cheat or extort money out of disaster victim residents for waste disposal services.

After the tornado volunteer center closed on May 14, postings on May 15 began focusing on health consultation for disaster victims and information on application procedures for official disaster certificates for tax exemptions, with other how-to information on official procedures being communicated through various channels. On May 17 and 18, news about disaster victim benefits such as free transportation, as well as briefings on reconstruction and support centers for residents, were publicized through the Tsukuba Civic Activities Cyber-Square. On May 21, information related to subsidies and loans was posted and the Facebook page for the Hojō Machikado newspaper was introduced. Live benefit concert information was posted on May 22, followed by further information on waste disposal two days later on May 24.

Figure 3: Dates of Postings and Categories from May 6 - May 26, 2012, Tsukuba Civic Activities CyberSquare

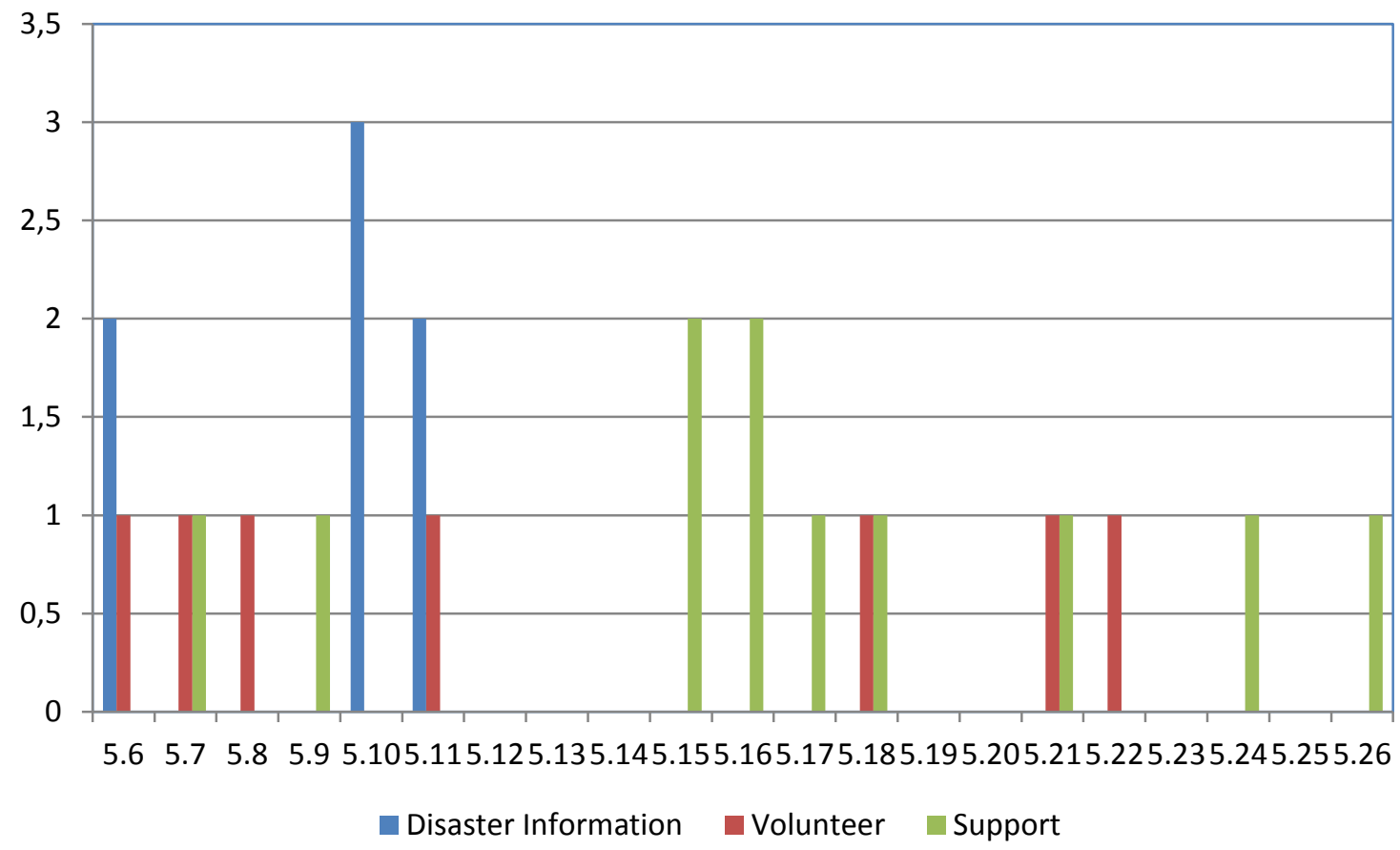

Table 3: Information about Posts during Tornado Disaster-Tsukuba Civic Activities Cyber-Square

\begin{tabular}{|l|l|c|c|c|c|}
\hline Date & Category & Reach & $\begin{array}{c}\text { Action by } \\
\text { User }\end{array}$ & $\begin{array}{c}\text { Talking } \\
\text { About }\end{array}$ & Communicated \\
\hline $2012 / 5 / 6$ & Disaster Info & 1,023 & 153 & 105 & $10.3 \%$ \\
\hline
\end{tabular}




\begin{tabular}{|c|c|c|c|c|c|}
\hline $2012 / 5 / 6$ & Disaster Info & 847 & 68 & 48 & $5.7 \%$ \\
\hline $2012 / 5 / 6$ & Volunteer & 771 & 60 & 40 & $5.2 \%$ \\
\hline $2012 / 5 / 7$ & Volunteer & 882 & 111 & 73 & $8.3 \%$ \\
\hline $2012 / 5 / 7$ & Support & 768 & 67 & 41 & $5.3 \%$ \\
\hline $2012 / 5 / 8$ & Volunteer & 823 & 75 & 47 & $5.7 \%$ \\
\hline $2012 / 5 / 9$ & Support & 780 & 66 & 44 & $5.6 \%$ \\
\hline $2012 / 5 / 10$ & Disaster Info & 749 & 44 & 31 & $4.1 \%$ \\
\hline $2012 / 5 / 10$ & Disaster Info & 740 & 62 & 31 & $4.2 \%$ \\
\hline $2012 / 5 / 10$ & Disaster Info & 723 & 28 & 21 & $2.9 \%$ \\
\hline $2012 / 5 / 11$ & Volunteer & 875 & 83 & 57 & $6.5 \%$ \\
\hline $2012 / 5 / 11$ & Support & 776 & 36 & 29 & $3.7 \%$ \\
\hline $2012 / 5 / 11$ & Support & 770 & 53 & 42 & $5.5 \%$ \\
\hline $2012 / 5 / 15$ & Support & 797 & 39 & 31 & $3.9 \%$ \\
\hline $2012 / 5 / 15$ & Support & 733 & 17 & 14 & $1.9 \%$ \\
\hline $2012 / 5 / 16$ & Volunteer & 762 & 42 & 31 & $4.1 \%$ \\
\hline $2012 / 5 / 16$ & Volunteer & 547 & 36 & 3 & $0.6 \%$ \\
\hline $2012 / 5 / 17$ & Support & 702 & 21 & 14 & $2.0 \%$ \\
\hline $2012 / 5 / 18$ & Support & 727 & 44 & 31 & $4.3 \%$ \\
\hline $2012 / 5 / 18$ & Volunteer & 700 & 35 & 28 & $4.0 \%$ \\
\hline $2012 / 5 / 21$ & Support & 673 & 22 & 17 & $2.5 \%$ \\
\hline $2012 / 5 / 21$ & Volunteer & 663 & 53 & 33 & $5.0 \%$ \\
\hline $2012 / 5 / 22$ & Volunteer & 720 & 51 & 31 & $4.3 \%$ \\
\hline $2012 / 5 / 24$ & Support & 631 & 21 & 15 & $2.4 \%$ \\
\hline $2012 / 5 / 26$ & Volunteer & 430 & 46 & 30 & $7.0 \%$ \\
\hline
\end{tabular}


Table 4: Category, Postings, Reach, Action, Talking about - Tsukuba Tornado May 6 to 26, 2012

\begin{tabular}{|l|l|c|c|c|}
\hline Category & Postings & Reach & $\begin{array}{c}\text { Action by } \\
\text { User }\end{array}$ & $\begin{array}{c}\text { Talking } \\
\text { About }\end{array}$ \\
\hline Disaster Information & 5 & 4,082 & 355 & 236 \\
\hline Volunteer & 10 & 7,173 & 592 & 373 \\
\hline Support & 10 & 7,357 & 386 & 278 \\
\hline Total & 25 & 18,612 & 1,333 & 887 \\
\hline Average Per Day & 1.3 & 980 & 70 & 47 \\
\hline
\end{tabular}

All postings from May 6 through May 16 had a reach of over 700, and subsequent postings had similar numbers. The May 26 posting related to the tornado relief concert and charity flea market for disaster-affected mothers and children had the lowest reach of 430 , although close to $7 \%$ of the viewers reposted the information (Table 3).

As can be observed from Table 3 and Figure 3, the postings can possibly be divided into three categories: 1) disaster information, 2) volunteering and 3) support. Initial information posted on the Tsukuba Civic Activities Cyber-Square was clearly about disaster information, however one week after the tornado, the main topic of the postings turned to support information for the disaster victims. Information related to volunteering was periodically distributed through the postings and actively assisted relief efforts. Information was disseminated swiftly during this period, although interactivity was not as high as one should expect from the mechanism of social networking sites such as Facebook.

The number of likes was higher than the preceding period of the Tsukuba Civic Activities Cyber-Square experiment, and the number of responses shows that information was being disseminated effectively. As the topic turned to support for the disaster victims one week after the tornado, the number of postings regarding information or facts about the tornado decreased in comparison to the first week immediately after the tornado (Figure 4). 
Figure 4: Likes and Talked about Concerning the May 6, 2012 Tornado Disaster, Tsukuba Civic Activities Cyber-Square (May 6 to May 26, 2012)

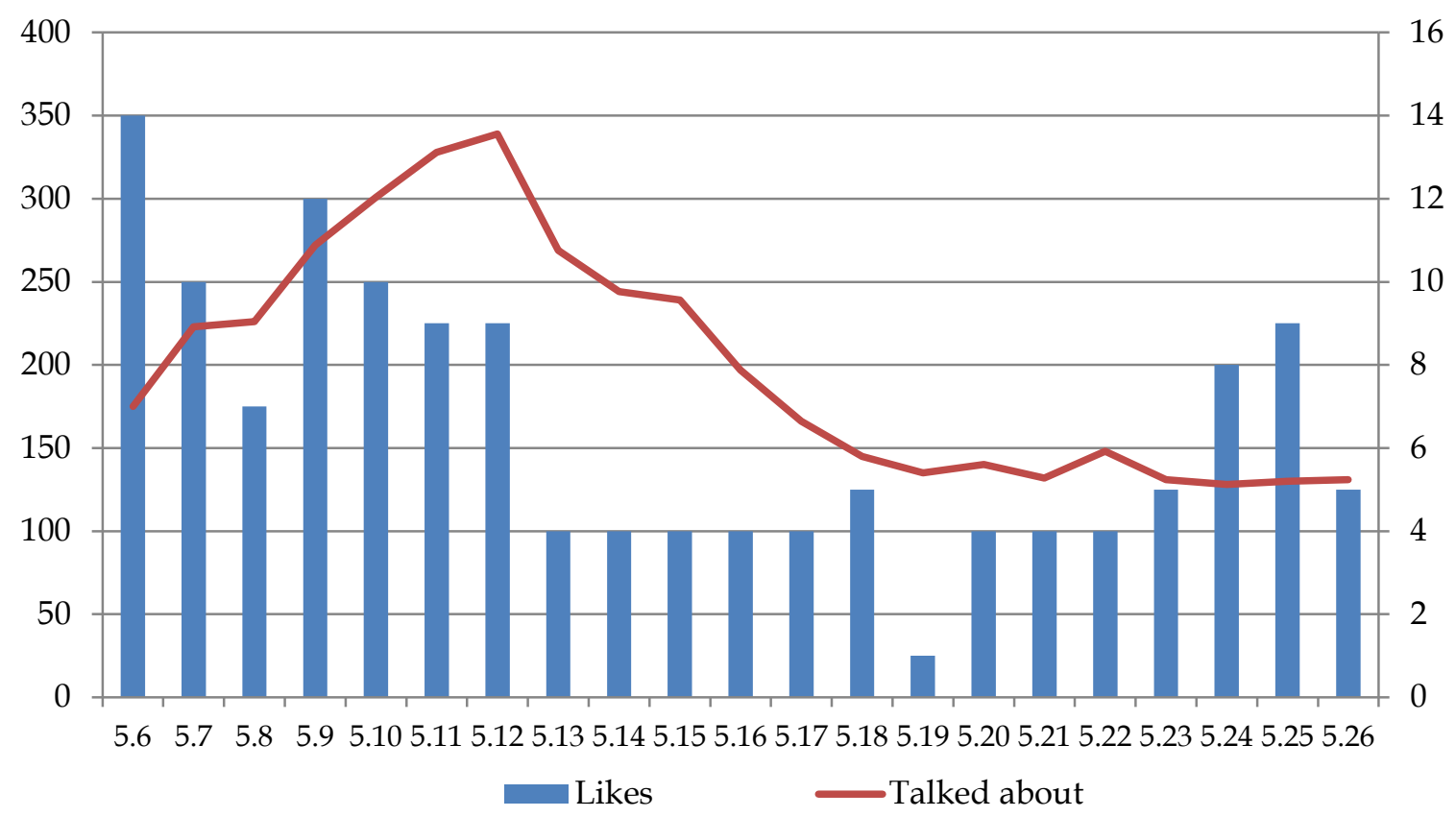

\section{Discussion}

This article analyzes the first phase of an experiment in SNS usage by the Tsukuba municipal government in Japan, focusing on the possibilities and problems of complementary communication channels. We described how municipalities are using SNS for enhancing civil society and how these services can provide vital information and connect citizens, municipal governments, and civil society. Although we speculated on the merits and demerits of the use of social networking services by municipal governments, our analysis of the practical experiment conducted by the Tsukuba municipal government during this six-month period highlighted both positive and negative aspects.

The main obstacle to initiating SNS usage by the Tsukuba municipal government prior to the experiment stemmed from a common anxiety held by many local governments. The fears of making mistakes in the postings and/or inadvertently spreading inappropriate information through social media, identified as common concerns among Japanese municipalities in the White Paper issued by the Ministry of Internal Affairs and Communications (2013), were also shared by administrators within the Tsukuba municipal government. To illustrate the background of this common anxiety among Japanese organizations, there have been incidents in the past where hotel restaurant personnel began posting private information about celebrity customers in the mainstream media via Twitter, and subsequently this scandalous information made its way back into the mainstream media, such as gossip tabloids and tabloid television (Asahi Shimbun, January 19, 2011 Evening Edition). The results were damaging to the organization that was reported in the news and took time for recovery because such information essentially lures trolls and results in 
creating long-term negative corporate images-in the case of this example, the restaurant and the hotel.

These past negative examples or instances in Japan have resulted in delaying or prohibiting social media usage among many organizations and have created a general fear of using social media among those with less-developed skills in managing or utilizing information technology. However, instead of shelving plans to use social media due to fear of trolls, the creation of guidelines was a vital step in the process of implementing the Tsukuba Civic Activities CyberSquare to avoid unwanted consequences of Internet usage that have been discussed in previous studies (Christopherson, 2007; Dwyer et al., 2007; Tufekci, 2007). The Tsukuba guidelines required that the municipality utilize social media that allowed users to use their real names, created procedures to avoid careless mistakes, had workers refrain from posting slanderous information, leaking secret and/or private information about the organization, avoid posting uncertain facts and clearly indicate when posting opinions that are the official position of the government. These guidelines were established through discussions within the Tsukuba government prior to the experiment. Many features of Facebook coincidentally satisfied the guidelines of using real names (in contrast to the Japanese SNS mixi which can be used anonymously) and were vital elements for initiating Facebook usage and completing this experiment to a successful first stage.

The Tsukuba Civic Activities Cyber-Square built a following of people who are relatively interested in civic activities and that can be mobilized quickly in disseminating information about volunteering, especially in the case of disaster relief as seen during the May 2012 tornado. SNS can therefore play a vital role in filling in the gap between the ordinary citizen and government, allow for more transparency, and create a community in cyberspace with people who have common interests. As we know from sociological studies, people within a similar environment with similar characteristics and similar experiences tend to form communities (homophily). Homophily within Facebook, especially with similar orientations (in this case, towards government and civic activities) is natural behavior, and with more time and accompanying the increase of users, the Facebook community can reflect onto the real world and society what is currently being seen in cyberspace. Outside of the context of this example, this may be seen as a problematic characteristic of SNS and cyberspace, however, in the case of government and civic activities, this can be viewed as a possibility.

In this article, we also examined how social media began to play a prominent role in information provision and communications during and after a disaster. The increase in Facebook usage in Japan has seen numerous municipalities attempting to use this platform to communicate more effectively with local citizens to cope with disasters. The example of Takeo city in Saga is one example, along with many others beginning to acquire Facebook accounts and attempting to reach out to local residents through this platform. The Tsukuba Civic Activities Cyber-Square Experiment is another example of how municipalities are endeavoring to use SNS platforms such as Facebook to improve communications and create positively oriented cyber communities in Japan. The findings of this study are confined to activities involving one municipality in Japan and one natural disaster, however, our results can be thought to be applicable in many situations. 
The tornado which hit Tsukuba city of Ibaraki prefecture in Japan on May 6, 2012 tested the municipal government in how it was able to handle a disaster, but also was an opportunity to observe how people would communicate on Facebook during a crisis through the Tsukuba Civic Activities Cyber-Square. The reach and reactions towards the posts on the Tsukuba Civic Activities Cyber-Square were considerably consistent with the previous literature advocating the potential effectiveness of social media during emergencies and disasters. We have observed that through social media, a communication network of social support was formed in Tsukuba when experiencing natural disasters like these, and social interaction was made possible in a wide region through social networking services.

During this tornado-inflicted disaster, the Tsukuba municipal government initially sent out disaster-related information and, quickly after, began sending out information about disaster volunteers and information on procedures for volunteering. In the days following the disaster, postings shifted towards more support for the disaster victims and information on events and ways to help these people. The occurrence of this tornado disaster in Tsukuba coincided with the Tsukuba Civic Activities Cyber-Square Experiment, so although the natural path of diffusion among the residents of Tsukuba city was altered, it was also an opportunity to demonstrate how social media such as SNS can play a possibly effective role in disaster-related information notification, enhancing civil society through volunteer coordination and later support and relief efforts.

Since the end of the experimental phase, the Tsukuba Civic Activities Cyber-Square has been incorporated into the daily operations of the Tsukuba municipal government. An increase in the size of the SNS community is fostering future possibilities of civic activities in the Tsukuba city area and offers other ideas and solutions to local municipalities on how to deploy SNS to further their causes. Many local governments in Japan are initiating the usage of social media platforms to virtually connect community members to confront an increasing number of social issues. These communities are following the steps taken by the Tsukuba municipal government to redesign themselves through using social media and recreate their communities.

\section{References}

Asahi Shimbun (January 19, 2011). Yumeijin ga raiten Twitter ni tōkōshitara [Tweeted about a celebrity visit to our restaurant] Asahi Shimbun Evening Edition, 6.

Baym, N. K. (2010). Personal connections in the digital age. Cambridge: Polity.

boyd, danah m. \& Ellison, N. B. (2007). Social Network Sites: Definition, History, and Scholarship. Journal of Computer-Mediated Communication, 13 (1), 210-230.

Christopherson, K. M. (2007). The positive and negative implications of anonymity in internet social interactions: On the internet, nobody knows you're a dog. Computers in Human Behavior, 23 (6), 30383056.

Dwyer, C., Hiltz, S. R., \& Passerini, K. (2007). Trust and Privacy Concern Within Social Networking Sites: A Comparison of Facebook and MySpace. Proceedings of AMCIS 2007. 
Ellison, N. B., Steinfield, C. \& Lampe, C. (2011). Connection strategies: Social capital implications of Facebook-enabled communication practices. New Media \& Society, 13 (6), 873-892.

Jennings, M. K., \& Zeitner, V. (2003). Internet use and civic engagement - A longitudinal analysis. Public Opinion Quarterly, 67 (3), 311-334.

Harper, R. (2002). The measurement of social capital in the United Kingdom. Country Paper prepared for OECD-ONS International Conference on Social Capital Measurement, London.

Hashimoto, Y., \& Ohama. A. (2014). The role of social media in emergency response: The case of the Great East Japan Earthquake. NIDS Journal of Defense and Security, No. 15 (2014). Retrieved August 7, 2015, from http://www.nids.go.jp/english/publication/kiyo/pdf/2014/bulletin_e2014_6.pdf

Howard P. N., Duffy, A., Freelon, D., Hussain, M. \& Mari W., Mazaid M. (2011). Opening Closed Regimes: What Was the Role of Social Media during the Arab Spring Project on Information Technology and Political Islam. Seattle: Department of Communication, University of Washington.

Howard, P. N. \& Parks, M. R. (2012). Social media and political change: Capacity, constraint, and consequence. Journal of Communication, 62 (2), 359-62.

Hughes, A. L. \& Palen, L. (2010). Twitter adoption and use in mass convergence and emergency events. International Journal of Emergency Management, 6(3-4), 248-260.

Inoue, T. (2013). Toward the operation guidelines for municipal social media account: From the analysis of user's behavior on Twitter in the Great East Japan Earthquake, International Journal of Information Society, 59(3), 137-145.

Kaigo, M. (2012). Social media usage during disasters and social capital: Twitter and the Great East Japan Earthquake. Keio Communication Review, 34, 19-35.

Kaigo, M. \& Tkach-Kawasaki, L. (2012). Social media usage for civil society in Japanese municipalities. in P. Parycek, M. Sachs \& M. Skoric (Eds.) CeDEM Asia 2012: Proceedings of the International Conference for E-Democracy and Open Government - Asia-2012. Krems: Edition Donau-Universitat Krems, 59-70.

Kakei, Y. (2013). Sōsharu Desain Jissen Gaido [A Practical Guide to Social Design] Tokyo: Eiji Press.

Kiss, J. (2015). Welcome to Jun, the town that ditched bureaucracy to run on Twitter. The Guardian (online). Retrieved August 7, 2015, from http://www.theguardian.com/technology/2015/jul/02/twitter-junspain-bureaucracy-local-government

Kobayashi, T. \& Ikeda, K. (2005). "Onrain komyuniti no shakaikanekishihon [Social capital in online communities]". In Ikeda K. (ed.) Intanetto komyunitii to Nichijōsekai [Internet Communities and Daily Life]. Tokyo: Seishin Shobo. 148-184.

Lampe, C., Ellison, N., \& Steinfield, C. (2007). A familiar Face(book): Profile elements as signals in an online social network Proceedings of Conference on Human Factors in Computing Systems (CHI 2007) New York: ACM Press. 435 - 444.

Livingstone, S., \& Markham, T. (2008). The contribution of media consumption to civic participation. British Journal of Sociology, 59(2), 351-371. 
Mills, A., Chen, R., Lee J. K. \& Rao H. R. (2009). Web 2.0 emergency applications: How useful can Twitter be in emergency response? Journal of Information Privacy \& Security (JIPS), 5(3), 3-26.

Ministry of Internal Affairs and Communications, Japan (MIC) (2013). Heisei Nijugonendo Jōhō Tsushin Hakusho. [Information and Communications White Paper 2013]. Tokyo: Ministry of Internal Affairs and Communications, Retrieved August 11, 2015, from http://www.soumu.go.jp/johotsusintokei/whitepaper/h25.html

Ministry of Internal Affairs and Communications, Japan (MIC) (2014). Chihōjichi Jōhōkanri Gaiyō (Denshi Jichitai no Suishin Jōkyō Heisei 26-nen 4-gatsu 1nichi genzai) [Local Government Information Overview (Implementation Status of E-Municipalities from April 1, 2014 to Present)]. Tokyo: Ministry of Internal Affairs and Communications, 17. Retrieved August 11, 2015, from http://www.soumu.go.jp/denshijiti/060213_02.html

Park, S. J., Lim, Y. S., Sams, S., Nam, S. M. \& Park, H. W. (2011). Networked politics on Cyworld: The text and sentiment of Korean political profiles. Social Science Computer Review 29, 288-299.

Pfeil, U., Arjan, R., \& Zaphiris, P. (2009). Age Differences in Online Social Networking - A Study of User Profiles and the Social Capital Divide among Teenagers and Older Users in MySpace." Computers in Human Behavior, 25(3), 643-654.

Putnam, R. D. (2000) Bowling Alone: The Collapse and Revival of American Community. New York: Simon \& Schuster.

Raacke, J., \& Bonds-Raacke, J. (2008). MySpace and Facebook: Applying the uses and gratifications theory to exploring friend-networking sites. Cyberpsychology \& Behavior, 11(2), 169-174.

Shah, D., Cho, J., Eveland, W., \& Kwak, N. (2005). Information and expression in a digital age - Modeling Internet effects on civic participation. Communication Research, 32(5), 531-565.

Shah, D. V., McLeod, J. M., \& Yoon, S. H. (2001). Communication, context, and community - An exploration of print, broadcast, and Internet influences. Communication Research, 28(4), 464-506.

Steinfield, C., Ellison, N. B. \& Lampe, C. (2008). Social capital, self-esteem, and use of online social network sites: A longitudinal analysis. Journal of Applied Developmental Psychology, 29, 434-445.

Sutton, J., Palen, L., \& Shklovski, I. (2008). Backchannels on the front lines: Emergent uses of social media in the 2007 Southern California wildfires. In Proceedings of the 5th International ISCRAM Conference (May 2008), 1-9.

Takahashi, T. (2010). Myspace or Mixi? Japanese engagement with SNS (social networking sites) in the global age. New Media and Society, 12(3), 453-475.

The Daily Yomiuri (May 8, 2012). Temperature differences spawned deadly tornado. Daily Yomiuri Online. Retrieved September 1, 2012 from http://www.yomiuri.co.jp/dy/national/T120507005103.htm

Tufekci, Z. (2007). On the Internet, everybody knows you're a dog: Presentation of self for everyday surveillance Paper presented at the American Sociological Association, 2007.

Valkenburg, P. \& Jochen, P. (2007). “Online Communication and Adolescent Well-Being: Testing the stimulation versus the displacement hypothesis. Journal of Computer-Mediated Communication, 12(4), 1169-1182. 
Wellman, B., \& Haythornthwaite, C. A. (Eds.). (2002). The Internet in everyday life. Malden, MA: Blackwell Pub.

Wellman, B., Quan-Hasse, A., Witte, J. \& Hampton, K. (2001). “Does the Internet increase, decrease, or supplement social capital?" American Behavioral Scientist, 45 (3), 436-455.

Wellman, B., Quan-Haase, A., Boase, J., Chen, W., Hampton, K., Isla de Diaz, I., \& Miyata, K. (2003). The social affordances of the internet for networked individualism. Journal of Computer- Mediated Communication, 8(3), 0 .

White, C. (2010). Social media and meta-networks for crisis mapping: Collaboratively building spatial data for situation awareness in disaster response and recovery management. Paper presented at 2010 Specialist Meeting Spatio-Temporal Constraints on Social Networks (University of California, Santa Barbara, Center for Spatial Studies, December 14-15, 2010). Retrieved August 11, 2015, from http://www.ncgia.ucsb.edu/projects/spatio-temporal/docs/White-position.pdf

\section{About the Authors}

\section{Muneo Kaigo}

Muneo Kaigo is an associate professor in the Faculty of Humanities and Social Sciences at the University of Tsukuba in Japan. He teaches courses in media communication in the Graduate School of Humanities and Social Sciences, media management in the Graduate School of Business Sciences, and communication science in the College of Comparative Culture at the University of Tsukuba. He is currently leading a joint research project on social media uses among local municipalities in Japan with cooperation from the municipal government of Tsukuba and Intel Corporation Japan. His recent research interests are also centered on the positive and negative information aggregation and flows in cyberspace.

\section{Leslie Tkach-Kawasaki}

Leslie Tkach-Kawasaki is an associate professor in the Faculty of Humanities and Social Sciences at the University of Tsukuba in Japan. Her research interests are mainly centered on how Japanese political actors utilize diverse Internet-based media channels for electoral campaigning and communication with the electorate. Recently, she has been involved in expanded projects involving the history of the Internet in Japan, Japanese politicians and social media network analysis, as well as cross-cultural differences in ethical and methodological approaches to Internet-based research. 